\title{
El derecho penal argentino y los desafíos de la participación ciudadana como derecho humano
}

Argentine criminal law and the challenges of citizen participation as a buman right $O$ direito penal argentino e os desafios da participação do cidadão como direito bumano Le droit pénal argentin et les défis de la participation citoyenne en tant que droit de l'bomme

阿根廷刑法与公民作为人权参与的挑战

\author{
Agatha Ciancaglini Troller ${ }^{1}$ y Jorge A. Filipini ${ }^{2}$ \\ Universidad de Buenos Aires - Argentina
}

Revista Derechos en Acción ISSN 2525-1678/ e-ISSN 2525-1686

Año 5/N 17 Primavera 2020 (21 septiembre a 20 diciembre), 237-258

DOI: https://doi.org/ https://doi.org/10.24215/25251678e459

Recibido: 01/05/2020

Aprobado: 15/09/2020

Resumen: El derecho de participación ciudadana es un derecho humano con contenido robusto (no limitado a la participación electoral), sin embargo, las normas penales en Argentina se debaten, crean, modifican y aplican sin intervención robusta de la ciudadanía. Esto pese a que existen vías institucionales y canales informales que buscan dar cumplimiento a este derecho. En este trabajo nos proponemos indagar

\footnotetext{
Abogada por la UBA, Especialización en Políticas Públicas y Justicia de Género (CLACSO), Docente UBA (ORCID: https://orcid.org/0000-0003-2687-2109).

2 Abogado (UBA), maestrando en Derecho Internacional de los Derechos Humanos (UBA) (ORCID: https://orcid.org/0000-0001-5805-8211)..
} 
los alcances de la participación ciudadana en los procesos de sanción de leyes, en la participación en casos judiciales y el juicio por jurados. Para esto, en primer lugar (I), analizaremos y contextualizaremos los alcances del derecho de participación en el ámbito del Derecho Internacional de los Derechos Humanos. Luego (II), evaluaremos si los canales de participación institucionales en el ámbito penal (y en general) son o no suficientes a la luz de las exigencias en materia de derechos humanos. Esto nos Ilevará a analizar (III) ciertos canales de participación no institucionalizados. Por último (IV), plantearemos los desafíos que enfrenta el derecho penal argentino para dar cumplimiento a los alcances de la participación ciudadana desde un enfoque de derechos humanos.

Palabras clave: derechos humanos - derecho penal - ciudadanía - participación ciudadana

Abstract: The right to public participation is a human right with robust content (not limited to electoral participation), however, criminal law in Argentina is debated, created, modified and applied without a strong intervention of the citizenship. This is despite the existence of institutional and informal mechanisms that seek to enforce the right to public participation. In this work we propose to investigate the scope of public participation on the law enforcement procedures, the participation in judicial cases and the jury trial. To this end, firstly (I), we will analyze and contextualize the scope of the right to participation in the field of international human rights law. Then (II), we will evaluate whether or not the institutional channels of participation in the criminal field (and in general) are sufficient in light of human rights standards. This will lead us to analyze (III) certain non-institutionalized channels of participation. Finally (IV), we will set out the challenges facing Argentina's criminal law in order to comply with the scope of public participation from a human rights perspective.

Keywords: human rights - criminal law - citizenship - public participation

Resumo: 0 direito à participação cidadã é um direito humano com conteúdo robusto (não limitado à participação eleitoral), no entanto, as regulamentações criminais na Argentina são debatidas, criadas, modificadas e aplicadas sem a intervenção robusta dos cidadãos. Isso apesar de existirem canais institucionais e canais informais que buscam o cumprimento desse direito. Neste trabalho propomos investigar o alcance da 
participação do cidadão nos processos de sanção de leis, na participação em processos judiciais e no julgamento por júri. Para isso, em primeiro lugar (I), analisaremos e contextualizaremos o alcance do direito de participação no campo do Direito Internacional dos Direitos Humanos. Em seguida (II), avaliaremos se os canais de participação institucional na esfera criminal (e em geral) são ou não suficientes à luz das demandas de direitos humanos. Isso nos levará a analisar (III) alguns canais de participação não institucionalizados. Finalmente (IV), apresentaremos os desafios enfrentados pelo direito penal argentino para cumprir o âmbito da participação cidadã desde uma perspectiva de direitos humanos.

Palavras-chave: direitos humanos, direito penal, cidadania, participação cidadã

Résumé: Le droit à la participation citoyenne est un droit humain avec un contenu solide (non limité à la participation électorale), cependant, les réglementations pénales en Argentine sont débattues, créées, modifiées et appliquées sans intervention solide des citoyens. Ceci malgré le fait qu'il existe des canaux institutionnels et des canaux informels qui cherchent à se conformer à ce droit. Dans ce travail, nous proposons d'étudier la portée de la participation citoyenne aux processus de sanction des Iois, à la participation aux affaires judiciaires et au procès par jury. Pour cela, en premier lieu (I), nous analyserons et contextualiserons la portée du droit de participation dans le domaine du droit international des droits de I'homme. Puis (II), nous évaluerons si les canaux de participation institutionnelle dans la sphère criminelle (et en général) sont ou ne sont pas suffisants au regard des revendications des droits de l'homme. Cela nous amènera à analyser (III) certains canaux de participation non institutionnalisés. Enfin (IV), nous présenterons les défis auxquels le droit pénal argentin est confronté pour se conformer à la portée de la participation citoyenne du point de vue des droits de l'homme.

Mot-clés: droits de l'homme, droit pénal, citoyenneté, participation citoyenne

摘要：公民参与权是一项内容充实的人权 (不限于选举参与) 但是阿 根廷的刑事法规在辩论制定修改和实施时没有公民的大力干预. 尽 管有一些机构渠道和非正式渠道试图遵守这项权利但事实并非如 此. 在这项工作中, 我们建议调查公民参与法律制定过程参与司法 案件和陪审团审判的范围. 为此, 首先 (I) 我们将分析国际人权法领 
域的参与权的范围并对其进行情境化然后(II)我们将根据人权要求 评估犯罪领域 (以及一般而言) 的机构参与渠道是否足够这将导致 我们分析 (III) 某些非制度化的参与渠道最后, 在人权方面, 我们将 提出阿根廷刑法在遵守公民参与范围方面面临的挑战

关键字: 人权, 刑法, 公民权, 公民参与

\section{Introducción $^{3}$}

Los Estados de la región latinoamericana se enfrentan continuamente con el desafío de afianzar y mejorar las condiciones de sus gobiernos democráticos. La región ha pasado desde formar parte de territorios conquistados por Estados europeos, períodos de pseudo-democracias (donde existían procesos electorales fraudulentos), dictaduras militares y, de un tiempo a esta parte, por procesos de consolidación y reforzamiento de las condiciones que hacen posibles la democracia, entendida a grandes rasgos como una forma de gobierno en el que las decisiones que afectan a todos son tomadas por la propia comunidad. En este sentido, partimos de considerar que las condiciones necesarias para la democracia son la participación ciudadana, la igualdad y el trato y la consideración de los ciudadanos (Nino, 1992).

Ahora bien, para consolidar el gobierno del pueblo -imperativo ineludible para la progresiva garantía de los derechos humanos en la región- es preciso reformular la estructura de poder de manera tal que el pueblo tome cada vez mayor intervención en los asuntos relevantes de la comunidad (Carta Democrática Interamericana, 2011, arts. 2 y 6). Sin embargo, notamos que en lo que respecta a las normas penales en Argentina se debaten, crean, modifican y aplican sin intervención robusta de la ciudadanía. Esto pese a que existen vías institucionales y canales

3 En este artículo se procuró evitar el lenguaje sexista. Sin embargo, a fin de facilitar la lectura no se incluyen recursos como "@", " $x$ " 0 "-a/as". En aquellos casos en los que no se pudo evitar el genérico masculino deseamos que se tenga en cuenta esta aclaración. 
informales que buscan dar cumplimiento al derecho de participación ciudadana. En este trabajo nos proponemos indagar los alcances de la participación ciudadana en los procesos de sanción de leyes, la participación en casos judiciales y el juicio por jurados. Para esto, en primer lugar (I), analizaremos y contextualizaremos los alcances del derecho de participación en el ámbito del Derecho Internacional de los Derechos Humanos. Luego (II), evaluaremos si los canales de participación institucionales en el ámbito penal (y en general) son o no suficientes a la luz de las exigencias en materia de derechos humanos. Esto nos llevará a analizar (III) ciertos canales de participación no institucionalizados. Por último (IV), plantearemos los desafíos que enfrenta el derecho penal argentino para dar cumplimiento a los alcances de la participación ciudadana desde un enfoque de derechos humanos.

\section{La participación ciudadana como derecho humano. Alcances}

Partiendo del reconocimiento de la voluntad del pueblo como la base de la autoridad del poder público (Declaración Universal de Derechos Humanos, 1948, art. 21), no es posible desconocer la estrecha vinculación existente entre los derechos humanos y la democracia. Así, la participación ciudadana en asuntos públicos constituye un derecho humano que, aunque esté inserto en la categoría de derechos civiles y políticos, se proyecta transversalmente a toda la nómina de derechos, cuyo ejercicio y protección hace posible.

Su consagración, tanto en el sistema universal de derechos humanos (Pacto Internacional de Derechos Civiles y Políticos, 1966, art. 25) como en el regional (Convención Americana sobre Derechos Humanos, 1969, art. 23), reconoce que "todos los ciudadanos gozarán, sin distinciones ni restricciones indebidas, del derecho a participar en la dirección de los asuntos públicos, directamente o por medio de representantes libremente elegidos." 
En Argentina la incorporación de dichos instrumentos internacionales de derechos humanos al bloque constitucional por medio del art. 75, inc. 22 de la Constitución Nacional reformada en 1994, implicó necesariamente la apertura a una concepción más amplia del concepto de participación ciudadana que originariamente se había limitado al derecho al voto de los representantes (Const., 1853, art. 22). En este sentido, si antes se vedaba toda intromisión directa por parte de la ciudadanía en asuntos públicos, reservando su actividad a la elección de los representantes, la reforma constitucional vino a reconocer, por medio de las referidas disposiciones de los tratados, el derecho a participar sin restricciones indebidas de la dirección de los asuntos públicos directamente o por medio de representantes.

Estas disposiciones gozan de la más alta jerarquía "en las condiciones de su vigencia" (art. 75, inc. $22 \mathrm{CN}$ ), lo que implica que rigen conforme a su efectiva aplicación por parte de los tribunales competentes para su interpretación y aplicación en el ámbito internacional (CSJN, S318:514, 1995). Ello obliga a repasar, y tener presente, la interpretación que los tribunales internacionales de derechos humanos han dado al derecho de participación, pues con ese alcance rigen en el sistema constitucional argentino. Al respecto, debe tenerse presente que la Corte Interamericana de Derechos Humanos (en adelante, Corte IDH) tuvo la oportunidad de interpretar los alcances de la disposición del art. 23 del Pacto de San José de Costa Rica al decidir en las casos "Yatama Vs. Nicaragua" (Corte IDH, 2005) y "Castañeda Gutman vs. Estados Unidos Mexicanos" (Corte IDH, 2008). Aunque ambos casos referían a la exclusión de candidaturas electorales, el referido tribunal interpretó que la participación política puede "incluir amplias y diversas actividades que las personas realizan individualmente $\mathrm{u}$ organizadas, con el propósito de intervenir en la designación de quienes gobernarán un Estado o se encargarán de la dirección de los asuntos públicos, así como influir en la formación de la política estatal a través de mecanismos de participación directa". (CoIDH, 2005: párr. 196) (CoIDH, 2008: párr. 146) 
En este sentido, en Yatama la Corte IDH señaló que:

[1]a evolución de los últimos lustros ha desarrollado sustantivamente el concepto del derecho a la participación en la dirección de los asuntos públicos que a estas alturas es un referente que incluye un espectro muy amplio de ingredientes que puede ir desde el derecho a promover la revocatoria de autoridades elegidas, fiscalizar la gestión pública, acceder a información pública, plantear iniciativas, expresar opiniones, etc. En efecto, la conceptualización amplia y general del derecho a 'participar en la dirección de los asuntos públicos', tal cual se encuentra literalmente expresado en la Convención, se ha afinado y ampliado. (CoIDH, 2005: párr. 13)

Además, indicó que "es indispensable que el Estado genere las condiciones y mecanismos óptimos para que [los derechos políticos] puedan ser ejercidos de forma efectiva, respetando el principio de igualdad y no discriminación." (CoIDH, 2005: párr. 195). De esta manera, brinda una concepción robusta del derecho a la participación ciudadana, cuyos alcances deben ser redefinidos en el contexto de consolidación de las democracias actuales. Concordantemente, en el ámbito universal, se señaló que la sociedad democrática se construye con la participación activa de quienes la conforman, "mas no se limita a una democracia electoral sino a una que garantice, con canales efectivos para la participación ciudadana, los derechos civiles, políticos, económicos, sociales y culturales" (PNUD, 2004)

En este mismo sentido la ex Alta Comisionada de Naciones Unidas para los Derechos Humanos, Navanethem Pillay, sostuvo que la participación incesante de la sociedad es indispensable para evitar las perturbaciones y las amenazas contra la democracia, con el propósito de mantener alejadas la "nostalgia de la dictadura" y las tentaciones de ir más allá del estado de derecho; existe una "vinculación permanente entre seguridad de las personas y convivencia democrática”. Y, además, que cuando se habla de participación, "algunos grupos de la sociedad merecen una atención e inclusión específicas [por esto] el 
empoderamiento de los grupos que han sido excluidos o marginados (...) y su plena participación en los procesos de toma de decisiones son fundamentales para el logro de la igualdad, el desarrollo y la paz" (ONU, 2012).

Por último, cabe mencionar que la Asamblea General de las Naciones Unidas, por Resolución 55/96, exhortó a los Estados a promover y consolidar la democracia mediante, entre otras cosas:

[1]a creación y la mejora del marco jurídico y los mecanismos necesarios para la participación amplia de todos los miembros de la sociedad civil en la promoción y la consolidación de la democracia (...) garantizando la existencia de mecanismos para consultar a la sociedad civil en los procesos de gestión de los asuntos públicos y para que ésta constituya a ellos y fomentando la cooperación entre las autoridades locales y las organizaciones no gubernamentales. (AG, 2001: 55/96)

Así, deviene ineludible interpretar en forma amplia el derecho de participación ciudadana en asuntos públicos como derecho humano fundamental para la protección de todos los derechos y la consolidación del sistema democrático. Esta interpretación robusta del estándar de protección y promoción del derecho de participación ciudadana implica que el Estado debe garantizar, sin restricciones indebidas, el ejercicio de acciones colectivas o individuales, sean institucionales $o$ informales, a través de las cuales se busque incidir en las decisiones sobre asuntos públicos que afectan a una comunidad o a sus miembros, lo que puede incluir todo tipo de actos encaminados a formar parte del debate, control, ejecución u oposición de las políticas públicas.

A partir de esta concepción amplia, debe admitirse que son múltiples y diversas las formas que puede adoptar la participación ciudadana; desde actos eleccionarios, movilizaciones, iniciativas de proyectos legislativos, acciones judiciales colectivas, juicios por jurados, hasta "escraches" a personas públicas. En lo que sigue, evaluaremos críticamente cómo se garantiza ese estándar en materia penal en el derecho argentino. 


\section{Las modalidades de participación institucional en materia penal en el sistema constitucional argentino}

En general, las formas de participación en materia penal pueden vincularse con cuestiones previas a la sanción de una norma o la adopción de una política determinada, o con cuestiones relativas a su ejecución y control posterior. A su vez, es posible diferenciar dos dimensiones distintas donde se manifiesta: por un lado la institucional (incluyendo la jurisdiccional) y por otra parte la participación informal.

Las modalidades de participación institucionalizadas se caracterizan por encontrarse previstas expresa y taxativamente mediante normas que las consagran y regulan en cuanto a su objeto, ámbito de aplicación, finalidad y procedimientos a cumplir. Las modalidades no institucionalizadas conglomeran las acciones participativas que tienen incidencia en la vida política de la comunidad pero que, no obstante estén amparadas por derechos y garantías constitucionales que legitiman su ejercicio, no están previstas ni reguladas como tales por normas jurídicas. Es preciso aclarar que esta categorización es puramente analítica, dado que el fenómeno de participación es siempre acumulativo en cuanto a sus modalidades.

\section{II.a. La participación institucionalizada como herramienta insuficiente para garantizar la participación ciudadana en el derecho penal argentino}

Analizaremos cómo se garantiza y promueve la participación ciudadana en relación con el derecho penal en el ámbito institucionalizado. Nos referiremos a los mecanismos de consulta e iniciativa popular, al juicio por jurados, a las audiencias públicas y a los "amicus curiae" ante la Corte Federal. ${ }^{4}$

\footnotetext{
4 Tomando en cuenta un concepto amplio de participación es posible considerar que las acciones ciudadanas tendientes a formar parte de la discusión y toma de decisiones en la arena jurisdiccional reconoce, como principal institución, la denuncia y querella penal, donde se reconoce una amplia legitimación de la ciudadanía para someter a la decisión de los
} 


\section{Consulta e iniciativa popular}

En el diseño constitucional argentino, la participación ciudadana se supeditó desde sus orígenes a la elección de los representantes (Const., 1994, arts. 1 y 22). De esta manera, el acto participativo por excelencia -y, en rigor, el único- era el eleccionario. Sin embargo, la reforma de 1994 trajo aparejada la consagración y regulación de dos mecanismos de intervención directa de la ciudadanía: la iniciativa y la consulta popular (Const., 1994, arts. 39 y 40)-

El mecanismo de iniciativa popular establece que todos los ciudadanos tienen derecho de iniciativa para presentar proyectos de ley ante la Cámara de Diputados de la Nación, cumpliendo ciertos requisitos formales que estipula una ley especial. En este sentido, el proyecto requiere la firma de un número no inferior al 1,5\% de los ciudadanos del padrón electoral, que representen al menos a seis distritos electorales, debe contener una exposición fundada de motivos y la nómina de los promotores, entre otros requisitos.

En segundo lugar, la consulta popular permite que los ciudadanos puedan expresar su aprobación o rechazo respecto de determinadas cuestiones que se someten a su consideración. Así, el electorado podría decidir directamente acerca de un asunto de interés sustantivo para el Estado; sobre el mantenimiento, modificación o derogación de una norma; o acerca de la gestión de un gobernante o gobierno. En el diseño constitucional argentino, la consulta popular es vinculante únicamente si es convocada por el Congreso a iniciativa de la Cámara de Diputados, al solo efecto de someter a la opinión ciudadana

\footnotetext{
jueces hechos que pudieran vulnerar el orden público. Asimismo, la acción de hábeas corpus consagrada en el art. 43 de la Constitución Nacional constituye otro de los mecanismos participativos, en tanto constituye una herramienta que permite ejercer un efectivo control sobre las autoridades y las condiciones de privación de la libertad y ejecución de las penas. Sin embargo, los límites de las mismas no serán tomadas en consideración en este artículo. 5 En rigor, la Constitución Nacional establece que la ley especial no puede requerir más del $3 \%$ del padrón. Véase: Gargarella, R. y Guidi, S. (2016)
} 
un proyecto legislativo (Const., 1994, art. 40). En tal supuesto, el voto ciudadano es obligatorio. En cambio, por medio de la consulta no vinculante, tanto el Poder Legislativo -con iniciativa de cualquiera de las Cámaras- como el Ejecutivo pueden someter diferentes materias de su competencia a la voluntad de los electores. En tal caso el voto del electorado no será obligatorio.

Ahora bien, ¿son suficientes estos espacios para asegurar un estándar amplio del derecho de participación ciudadana en materia penal? La respuesta es negativa. En lo que respecta a la iniciativa popular, la efectividad en términos de participación parece bastante acotada ya que las exigencias impuestas demuestran que es un mecanismo poco accesible para la ciudadanía. La forma en que debe estar redactado el proyecto, la cantidad de adherentes que lo deben suscribir y particularmente los distritos que deben representar determinan que este procedimiento sea dificultoso para los ciudadanos que pretenden promover una iniciativa en el Congreso. Estos resguardos buscan limitar las propuestas individuales o que carezcan de apoyos fuertes y, a su vez, se convierten en mecanismos poco efectivos para la participación espontánea de sectores que no tengan el apoyo de organizaciones. En este sentido, el apoyo de ONGs resulta fundamental (Batch, 2004). Creemos que todo ello ha debido influir en la escasa utilización de dicho mecanismo de participación desde su creación. A modo de ejemplo, entre 1996 y 2011 se han presentado 41 iniciativas populares, es decir, poco más de dos iniciativas por año (Sancari, 2016). Además, y sobre todo, nos interesa señalar que en materia penal, la iniciativa popular ha sido -junto a otras materias- expresamente vedada por el constituyente, lo cual constituye un valladar insalvable para la participación ciudadana. En efecto, la Constitución ha reservado la creación de normas penales exclusivamente al Congreso (Const., 1994, art. 99, inc. 3, 39 y 76). Esta restricción podría tener como principal finalidad preservar de eventuales manipulaciones a la opinión pública respecto de temas que se estimaron críticos (Gelli, 2003). Sin embargo, en lo que respecta concretamente a la materia penal, la restricción se justificó en la 
desconfianza de la participación ciudadana directa en asuntos públicos sensibles. ${ }^{6}$ Volveremos sobre el punto más adelante.

En cuanto al mecanismo de consulta popular, la Constitución Nacional no excluye materias determinadas, como así tampoco limita en tal sentido la ley 25.432 que lo regula, ${ }^{7}$ de manera que sería una vía habilitada para la intervención directa de la ciudadanía en el diseño de la legislación penal. De todos modos, hasta el presente no se ha sometido a consulta popular ningún proyecto de ley o asunto en materia penal. En rigor, la herramienta no ha sido utilizada desde su consagración constitucional en ninguna materia. El único antecedente lo constituye la consulta popular relativa al conflicto entre Argentina y Chile relativo al canal de Beagle, anterior a la reforma del año 1994.

Así, la consulta popular tal como fue consagrada consiste en un mecanismo cerrado de participación. Ello porque no

6 Al momento de discutirse el proyecto elaborado por la Comisión de Redacción respecto de los mecanismos de consulta e iniciativa popular, Raúl R. Alfonsín destacó que "(...)sabemos que a veces la opinión es pasajera, mientras que la democracia representativa nos brinda la posibilidad de que hace que el pueblo no esté sujeto a los vaivenes de la moda o de una campaña. Aquí se ha criticado esta posición, que es fruto de nuestra prudencia. No queremos consultas vinculadas con lo penal, porque en un arrebato de la opinión pública podemos llegar a establecer, por ejemplo, la pena de muerte por un delito. Tratada esta cuestión de manera particular por los medios de difusión, podría llevar de pronto, en una explosión de la sociedad, a tolerar o permitir una deformación de esta magnitud (...) Necesariamente tenemos que ser prudentes en un tema de esta magnitud. Estamos haciendo retrotraer desde el Congreso al pueblo lo que el pueblo le había dado a sus representantes(...)". La única opinión disidente fue expresada por Horacio Conesa Mones Ruiz para quien los mecanismos consagrados "no satisfacen los verdaderos deseos de la sociedad; son limitativos y han sido hechos a medias (...) El párrafo tercero se determina que no serán objeto de iniciativa popular los proyectos referidos a reforma constitucional, tratados internacionales, tributos, presupuesto y materia penal. No entendemos la razón de esta limitación." Véase: Diario de sesiones de la Convención Nacional Constituyente (1994)

7 Dicha ley excluye del mecanismo de consulta popular aquellos proyectos cuyo trámite esté previsto para una cámara de origen exclusiva o con mayorías calificadas, incluso para el caso de consulta no vinculante. Por otra parte, la ley establece que para que la consulta sea válida debe participar al menos el 35\% de los ciudadanos habilitados. El proyecto que obtiene mayoría de votos afirmativos se convierte automáticamente en ley. En cambio, cuando la consulta no es vinculante, si es aprobado por los electores, el Congreso tiene la obligación de tratarlo. 
depende de la iniciativa ciudadana sino de los representantes que son quienes deciden escuchar a la ciudadanía o no hacerlo. Pero, además, es un mecanismo insuficiente en términos de expresión del pueblo, ya que consiste en un procedimiento de formulación simple de casos que por lo general suelen ser complejos, frente a lo cual la ciudadanía solo puede expedirse afirmativa o negativamente. Puesto en contexto de cualquier decisión pública relevante, es claro que ese mecanismo es insuficiente. Así lo demuestra, por ejemplo, el referéndum de paz celebrado en Colombia en octubre de 2016, donde se llamó a la ciudadanía a aprobar o rechazar los acuerdos que el gobierno había suscripto con la guerrilla de las Fuerzas Armadas Revolucionarias de Colombia (FARC). El resultado fue una victoria del "No" al acuerdo. Ese resultado inesperado por el gobierno colombiano dejó interrogantes incontestables: ¿qué quiso decir el pueblo colombiano cuando dijo "no" al acuerdo con las FARC? ¿Que no quieren la paz? ¿No quieren esa paz? ¿No quieren ninguna paz? Y el amplio sector que votó por el "Sí" ¿pretende la paz a cualquier costo?

De esta manera, ninguna de estas herramientas constituyen formas genuinas de participación ciudadana, en la medida que no representan un amplio ejercicio del derecho a participar en la decisión de los asuntos públicos.

\section{El juicio por jurados}

El juicio por jurados (arts. 24, 75 inc. 12 y $118 \mathrm{CN}$ ) constituye una importantísima herramienta de participación ciudadana. El jurado popular como sistema de enjuiciamiento se conforma por doce ciudadanos legos que deliberan, en secreto y sin intromisiones externas, para arribar a un veredicto acorde a su sentido común, en base a la producción de prueba durante la audiencia de debate y con la ayuda de guías jurídico-técnicas suministradas por un juez y elaboradas con intervención de las partes. Este modelo es el que mejor se ajusta a los valores republicanos y liberales constitucionales (y ahora de estándares 
de derechos humanos), que rechazan cualquier tipo de desconfianza en el pueblo soberano, como la que algunas veces lleva a la negación de la participación ciudadana en la administración de justicia, y otras a la intromisión de un funcionario estatal en funciones exclusivas del jurado.

Llamativamente en Argentina, y pese a los contundentes términos constitucionales, habiendo transcurrido ya más de un siglo y medio de su consagración las causas criminales continúan -al menos en el sistema procesal penal federal y en la mayoría de los provinciales- siendo juzgadas exclusivamente por jueces profesionales. No es el propósito de este trabajo dar tratamiento a los distintos argumentos que se han ido elaborando para justificar el apartamiento de la Constitución; sólo nos interesa señalar que, en la mayoría de esas justificaciones, subyace el arraigo a una visión sobre la naturalidad de los jueces profesionales en la decisión de las causas criminales y, una profunda desconfianza en la decisión de la ciudadanía, prefiriendo reservar el monopolio del poder represivo en las agencias estatales.

Tales argumentos serán retomados sobre el final de este trabajo, basta ahora con señalar que se encuentra cerrada aquí también, entonces, toda posibilidad de participación ciudadana en materia de aplicación concreta del derecho penal, ya que el juicio por jurados no ha sido establecido como garantía al justiciable, pero tampoco de la ciudadanía como forma de involucramiento en los asuntos públicos.

\section{Las audiencias públicas y los amicus curiae ante la CSJN}

Otros mecanismos de participación lo constituyen las audiencias públicas (CSJN, Acordada 30/2007) con el objeto de convocar a la ciudadanía a opinar sobre asuntos públicos de relevancia que estén pendientes de resolución por el más alto Tribunal y la posibilidad de intervenir mediante la presentación de amicus curiae (amigos del tribunal) a fin de dar una opinión fundada sobre un tema o caso específico sometido a la decisión del Tribunal (CSJN, Acordada 28/2004 y 7/2013). 
Pareciera que estos mecanismos se tornan también insuficientes debido a - un elevado tecnicismo; -no obligatoriedad o influencia en las decisiones finales; - su aceptación o rechazo queda en manos del tribunal. En este sentido, sostienen Benedetti y Sáenz que si bien se trató de la "apertura de una puerta" por la que distintos actores pueden, además de "ver" la actividad de la Corte, "entrar a ella" e intervenir en alguna de sus tareas, se trataron de medidas más bien caracterizadas por la transparencia que por el incentivo a la participación. (Benedetti, M.A, Sáenz, M.J., 2016).

Asimismo, las audiencias carecen de todo tipo de fuerza legal y la convocatoria a las mismas está supeditada al criterio de los integrantes del tribunal. Así fue como desde la primera audiencia pública que tuvo lugar en el año 2004 (causa Verbitsky, que junto a "Mendoza" y "Grupo Clarín" precedieron la acordada 30/2007 que reguló expresamente la práctica) hasta el año 2019 se celebraron audiencias públicas en tan sólo 37 causas. ${ }^{8}$ Las mismas insuficiencias se detectan respecto de la posibilidad de constituirse como amicus curiae.

Las audiencias públicas como la presentación de amicus curiae podrían ser herramientas valiosas como medio para dar respuesta a las críticas que se formulan al poder judicial como poder contra mayoritario y a la vez intérprete constitucional (Gargarella, 1996). Sin embargo, por cómo han sido reguladas no constituyen un canal de participación suficiente, situación que se refuerza cuando se analiza que ni siquiera ha sido utilizado en casos donde se discuta la aplicación del derecho penal. Ello, porque se ha caído nuevamente en la desconfianza de la ciudadanía.

De esta manera, los mecanismos existentes para garantizar la participación ciudadana en asuntos públicos y en especial en materia penal, se tornan insuficientes por no responder a una

\footnotetext{
8 Centro de Información Judicial (CIJ), Audiencias Públicas ante la CSJN. Disponible en: http://www.cij.gov.ar/audiencias.html
} 
concepción robusta como la que postula el entendimiento de la participación ciudadana como un derecho humano.

\section{La participación informal (no institucional) en materia penal}

Existen también otras formas de participación, que quedan amparadas en directa relación con otros derechos fundamentales, tales como la libertad de expresión, de reunión, de huelga y petición ante las autoridades, entre otros. Excede el marco de este trabajo toda esquematización que abarque el conjunto de acciones participativas informales, pero a partir de ejemplos concretos pretendemos significar cuál es la posible incidencia que estas herramientas pueden tener en el sistema penal argentino.

Entre los factores tradicionales de participación ciudadana que tienen directa incidencia en materia penal encontramos las marchas y protestas sociales. En la mayoría de los casos, la ciudadanía se moviliza en reacción frente a episodios graves o reiterados de inseguridad, marcando el descontento con políticas criminales ineficaces, exigiendo justicia o repudiando decisiones judiciales determinadas. Entre ellos cabe destacar las sucesivas marchas por el homicidio del fotógrafo José Luis Cabezas, por el atentado a la Amia, por el asesinato de Marita Verón, los reclamos de Blumberg, las reiteradas marchas en repudio de la violencia de género con el reclamo "Ni una menos" y las marchas por el Aborto Legal, Seguro y Gratuito (Tarducci, 2018)

En los últimos años, las modalidades de participación no institucionalizada han visto surgir simultáneamente nuevas herramientas y modalidades de participación, producto de la naciente "sociedad del conocimiento", caracterizada por la innovación de las tecnologías de la información y las comunicaciones, donde el incremento de la información modificó la forma en que se desarrollan muchas actividades en la sociedad moderna (Canclini García, 2004). En tal sentido, primero internet y luego las redes sociales, han dado lugar a novedosas modalidades de participación. 
Las redes sociales tienen inconmensurable alcance y permiten, a veces desde el anonimato, alcanzar un público ilimitado. Ello las ha convertido en una atractiva herramienta para receptar demandas sociales que antes resultaban difíciles de canalizar o de ser difundidas entre una gran cantidad de personas. Principalmente por el acceso a información que antes no estaba disponible sumado a la posibilidad de participar activamente de los debates y formular denuncias. En el continente son incontables los casos en los que las redes sociales han "viralizado" denuncias de damnificados e imágenes y videos que dan cuenta de delitos cometidos a cualquier miembro de la comunidad. También son conocidos los "escraches" públicos de personas a las que se les acusa desde el maltrato animal, la contaminación ambiental y hasta de abuso sexual. En definitiva, abundan ejemplos que no harían más que distraer nuestra atención.

Tanto las modalidades tradicionales -protestas- como las que se gestaron a partir de las nuevas tecnologías, son fenómenos complejos que involucran más de una modalidad de participación e, incluso, a diversos actores sociales, con concretas incidencias -creemos- en la sanción y ejecución de normas penales. Básicamente porque estas formas constituyen un espacio propicio para compensar los límites o insuficiencias de otras formas de participación institucionales (Sancari, 2016). En este sentido, las redes sociales, aunque seguramente con limitados alcances jurisdiccionales pero no por ello poca repercusión, ofrecen un espacio para denunciar públicamente sin correr riesgos ni someterse a procesos judiciales.

Por otra parte, se verifica un crecimiento del nivel de participación informal en asuntos relacionados con el derecho penal, lo que trae aparejado un nuevo escenario de discusión. Los ciudadanos están altamente informados, se involucran en cuestiones públicas y denuncian la comisión de delitos que no encuentran reparo en las vías institucionales. Ello implica quitar la exclusividad académica a los debates propios del derecho penal. Es decir que la opinión pública debata abiertamente, 
con nuevos elementos y fundamentos de los más diversos, las problemáticas de la disciplina penal que antes quedaban reservadas exclusivamente a los profesionales del derecho.

Esto no siempre se traducirá en un escenario más favorable para la toma de decisiones en términos democráticos, pues las iniciativas espontáneas de la ciudadanía, canalizadas por medios informales, suelen ser poco proclives a permitir la participación en el debate de los distintos actores involucrados.

Por último, en cuanto a los efectos concretos de estas modalidades, creemos que si bien se consideran pocos los casos de las demandas sociales que son receptadas por las vías institucionales mediante la sanción de leyes o ejecución de políticas criminales (por ejemplo con motivo de los reclamos masivos por el asesinato de Marita Verón, se ha sancionado la ley de trata 9 de todos modos la sola existencia -y garantía por parte del Estado- de canales informales de participación ciudadana inciden directamente en el sistema penal, en tanto logran poner el tema (reclamo) en la agenda política. Así, no siendo posible promover una reforma legislativa ni participar de la decisión de los casos judiciales, sí puede el ciudadano incidir (levemente) por esta vía en esas decisiones.

Sin embargo, es interesante analizar cuál es o debería ser el alcance de las demandas efectuadas de esa manera. A esto nos dedicaremos en el siguiente apartado.

\section{Nuevas vías de participación institucional de la ciudadanía: del miedo infundado a una imperiosa necesidad republicana}

Una de las obligaciones del Estado consiste en asegurar y promover las amplias vías de participación por las cuales la ciudadanía tiene derecho a influir, directa o indirectamente, en

9 La Nación, "Diputados aprobó por unanimidad la reforma a la ley contra la trata de personas.", 2012. Disponible en: http://www.lanacion.com.ar/1538729-diputados-aprobopor-unanimidad-la-reforma-a-la-ley-contra-la-trata-de-personas 
la decisión de los asuntos públicos. Esa exigencia en materia de derechos humanos consiste en abrir canales de diálogo e intervención efectiva de la ciudadanía en miras de consolidar el sistema democrático. Ahora bien, la existencia de mecanismos institucionales receptivos de la participación directa de la ciudadanía es insuficiente en Argentina, lo que conlleva a que la misma ciudadanía opte por mecanismos informales para lograr incidir en los asuntos públicos en general y en el funcionamiento del sistema penal, en particular. De esta manera, es necesario preguntarse ¿por qué se impide a la ciudadanía participar en la creación y aplicación de las normas penales? ¿Existen argumentos que justifiquen que esa potestad siga reservada excluyentemente a funcionarios del Estado?

El acotado -en rigor inexistente- margen de participación institucional de la ciudadanía en materia penal encuentra como única justificación la profunda desconfianza -generalmente atribuida a la doctrina liberal ${ }^{10}$ - a la intervención del pueblo en tales asuntos, creyendo que conduce a la irracionalidad y a la violencia. Se asume que cualquier vínculo efectivo entre la ciudadanía y un hecho criminal es susceptible de terminar en hordas de venganza. Ese temor cae en el error de creer adivinar lo que las mayorías podrían decidir. Así, se piensa que, si se somete a la decisión popular directa la creación de normas penales éstas serán agravadas hasta el absurdo, que si se permite decidir la aplicación de tales normas a jurados populares lo harán de la forma más severa para saciar las ansias de venganza, que si se escucha a los ciudadanos en el marco de procesos colectivos que los afectan, o bien en el ámbito de audiencias públicas en casos judiciales relevantes, su opinión carecerá de utilidad para llegar a la solución más adecuada.

Pues bien, sobran los ejemplos que nos permiten sostener que esos temores son infundados. Son claros los recientes ejemplos del plebiscito por la paz en Colombia y el "brexit" británico,

10 Diario Judicial, "Zaffaroni: "yo no sé si el juicio por jurados puede funcionar", 2015. Disponible en: http://www.diariojudicial.com/nota/35719 
donde se creía que la convocatoria a consulta popular de dos decisiones trascendentales en la vida pública de la sociedad serían decididas en un sentido por las mayorías y la sorpresa estuvo dada por la decisión contraria. También en materia jurisdiccional contamos con evidencias empíricas que nos permiten contrastar esos argumentos antidemocráticos. Así, por ejemplo, los estudios empíricos que se han realizado en torno a las primeras experiencias de jurados en Argentina, sugieren que los jurados legos han tendido a ser, sistemáticamente, menos punitivistas que los jurados técnicos (Bergoglio, M. I., et. al., 2009). A su vez, en algunos casos, se demostró que jurados y jueces coincidieron en los veredictos propuestos en un porcentaje cercano al $75 \%$ de todos los juicios. Y lo más relevante es que, cuando estuvieron en desacuerdo, el jurado fue siete veces más propenso a ser menos severo, ya sea absolviendo al acusado o condenándolo por un delito menor que los jueves (Zimring, Franklin E., 2003).

En todo caso, frente a un temor como el expresado en términos de populismo punitivo, por más fundado que pudiera considerárselo, no puede conducir al completo desconocimiento del derecho de participación. Más bien el desafío es el de la formación ciudadana del pueblo, basada en los principios democráticos, el respeto a los derechos humanos y las responsabilidades sociales. Ese es el camino que necesariamente debe emprender cualquier democracia participativa. Así, el papel fundamental de los organismos públicos es el de promover y proteger los derechos humanos desde la educación, antes que optar por la exclusión de la ciudadanía en las decisiones públicas.

Pero, además, otro contra argumento de peso que resulta concluyente para demostrar infundado el temor a la participación ciudadana en materia penal es que creemos que no existen razones que justifiquen temer del pueblo lo que no se teme de los gobernantes. Acaso, ¿hay razones suficientes para considerar que, por ejemplo, los legisladores no podrían, movilizados por alguna razón puntual, agravar excesivamente las penas? 
Incluso, ¿no existen más probabilidades de que sea un grupo reducido de representantes quienes se dejen llevar por la irracionalidad o una pulsión de venganza? ¿No es posible considerar que la judicatura pueda motivar sus decisiones en el mismo sentido? Esas preguntas retóricas podrían responderse alegando que, si fueran los representantes del pueblo o los/as funcionarios judiciales quienes actuaran incorrectamente, existen resortes institucionales dentro de cada poder y un sistema de frenos y contrapesos para solucionarlo. Así, por un lado, el control de constitucionalidad de las leyes no permitiría un exceso del poder legislativo, a la vez que una inadecuada sentencia judicial sería revocada mediante los recursos procesales previstos. Pues bien, solo debe señalarse que tales herramientas también serían útiles en el caso -como se dijo menos probable- de que esas erróneas decisiones fueran adoptadas por la ciudadanía. Entonces, si se teme al agravamiento desproporcionado o incluso a la reinstauración de la pena de muerte hay que contestar que ello es susceptible de ser invalidado por el propio sistema. Si se teme a la errónea aplicación de la ley por los jurados populares, hay que contestar que, en todo caso, se trata de proveer al proceso de herramientas que permitan aquí también revocar decisiones injustas.

Consideramos que el desafío para volver a legitimar al derecho penal en el contexto democrático consiste en el tendido de puentes entre la ciudadanía y la creación, aplicación e interpretación de las normas. En este sentido, las normas, y en general las decisiones concernientes a asuntos públicos, no deben constituir un producto respecto del cual los ciudadanos se consideren ajenos. La ciudadania deben comprender, aceptar y elegir cómo aplicar esas normas; no ser meras víctimas o testigos de las mismas. Así, la democratización del derecho penal supone, además, la construcción de un derecho penal que hable el lenguaje del pueblo. Sostiene Gargarella que es importante que las leyes no sean creadas y puestas en ejecución por individuos completamente separados de aquellos que tienden a sufrir 
el impacto de las mismas. De lo contrario "el derecho penal, en definitiva, pierde respetabilidad si los individuos carecen de buenas razones para creer que el mismo refleja de modo apropiado sus intereses y puntos de vista" (Gargarella, R., 2007)

\section{Conclusiones}

La participación ciudadana es entonces un derecho humano que permite el disfrute de la ciudadanía. En este sentido, debe ser interpretado en forma amplia. Conforme el derecho internacional de los derechos humanos los canales de participación no se pueden limitar a la participación electoral más o menos periódica. En materia penal, no existen argumentos suficientes para no garantizar la participación robusta de la ciudadanía. Sin embargo, las normas penales en Argentina se debaten, crean, modifican y aplican sin intervención robusta de los ciudadanos. Pese a que existen vías institucionales, tanto en el ámbito legislativo como en el judicial, las mismas son insuficientes o directamente se encuentran vedadas para el ámbito penal. Esto ha generado nuevas modalidades informales de participación que inciden en la adopción de políticas públicas.

Ahora bien, en materia penal la participación de la ciudadanía vía canales informales tiende a ser muy acotada. Esto puede tener fundamento en el temor a las reacciones injustificadas por parte de ciertas mayorías. Sin embargo, la interpretación robusta del derecho a la participación ciudadana no puede basarse en este tipo de temores. Por el contrario, implica generar espacios de reforzamiento de la formación ciudadana en la toma de decisiones públicas. Luego, el desafío para consolidar las democracias constitucionales de la región implica que los puentes entre la ciudadanía y la toma de decisiones deban necesariamente apoyarse en la confianza en las capacidades de la ciudadanía. 